\title{
Intensity of contact with frontline workers and its influence on maternal and newborn health behaviors: cross-sectional survey in rural Uttar Pradesh, India
}

Tanica Lyngdoh ${ }^{1,4^{*}}$, Sutapa B. Neogi ${ }^{1}$, Danish Ahmad ${ }^{2}$, Srinivasan Soundararajan ${ }^{2}$ and Dileep Mavalankar ${ }^{3}$

\begin{abstract}
Background: India is committed to improving maternal and newborn health in order to achieve the targets for India's Millennium Development Goal 4. Considering their role as a link between community and health systems, frontline workers (FLWs) can be effectively utilized in strengthening maternal and newborn care. In this paper, we set out to examine the effect of intensity of contact with FLWs on key maternal and newborn health behaviors and to determine if this association varies by status of Self Help Group (SHG) membership.
\end{abstract}

Methods: This population-based cross-sectional study included 2208 currently married women aged 15-49 years who had delivered a baby during the last 15 months prior to the survey and selected through a multi-stage cluster sampling from rural villages and urban wards. The outcome of interest included variables related to key knowledge and practice of healthy behavior in relation to maternal and newborn health and exposure variable considered was intensity of contact with FLWs.

Results: Of the women interviewed, 1729 (78\%) belonged to SHG household. For knowledge on the need for at least 3 antenatal care (ANC) check-ups, two tetanus toxoid (TT) injections and consumption of 100 or more ironfolic acid (IFA) tablets, proportion of those who were aware of these practices increased with increasing number of contacts with FLWs $(P$ value $<0.001)$. Practice for $\Pi$ injections showed an increasing trend with increasing number of contacts with FLW. An increase in the odds of delivering in an institution was observed in those who had higher number of contacts as compared to those with no contacts ( $P$ value $<0.001$ ). With regard to newborn healthy behavior practice, breastfeeding within $1 \mathrm{~h}$ of delivery showed significant association and the odds of this practice improved in those who had $\geq 3$ contacts with FLW as compared to those had no contacts. Except for consumption of 100 or more IFA tablets, there was no interaction of these associations by SHG status.

Conclusion: There was an overall low prevalence of both knowledge and practice of key maternal and newborn healthy behaviors and only a few of these were associated with frequency of contacts with FLW. Findings not only highlight the urgent need for effectively leveraging FLWs to strengthen maternal and newborn care but also to improve the quality of services provided by them.

\footnotetext{
* Correspondence: tanica.lyngdoh@iiphd.org

${ }^{1}$ Indian Institute of Public Health Delhi, Public Health foundation of India,

New Delhi, India

${ }^{4}$ Indian Institute of Public Health Delhi, Public Health foundation of India,

Plot No. 47, Sector-44, Institutional Area, Gurgaon 122002, India

Full list of author information is available at the end of the article
}

(c) The Author(s). 2018 Open Access This article is distributed under the terms of the Creative Commons Attribution 4.0 International License (http://creativecommons.org/licenses/by/4.0/, which permits unrestricted use, distribution, and reproduction in any medium, provided you give appropriate credit to the original author(s) and the source, provide a link to the Creative Commons license, and indicate if changes were made. The Creative Commons Public Domain Dedication waiver (http://creativecommons.org/publicdomain/zero/1.0/) applies to the data made available in this article, unless otherwise stated. 


\section{Background}

Despite the commitment and concerted effort in adopting the framework laid down under the Millennium Development Goals (MDGs), India has failed to achieve the targets, in particular, reduction in Maternal Mortality Ratio (MMR) and Infant Mortality Rate (IMR) [1, 2]. Post 2015, the Sustainable Development Goals (SDGs) have set the agenda for prioritizing maternal and newborn health by applying lessons learnt from the MDGs and are working towards developing strategies that will achieve a steeper decline. Aggressive steps at this point are crucial to accelerate the progress in reducing maternal and newborn mortality in order to meet the SDG targets.

The health of mothers and newborns are closely related and interventions to prevent mortality essentially apply to both. It is well known that improvements in maternal and newborn health does not necessarily require high-tech, complex interventions. Even though simple measures like antenatal care, clean birth practices, essential newborn care, early initiation, and exclusive breastfeeding can go a long way to bring about positive impact, yet gaps persist in the practice of good maternal and newborn health behaviors. Globally, there is increasing interest in the role of frontline workers (FLW) as an effective tool in bridging this gap. Community-based strategies involving the expanded use of FLWs as a link to health system strengthening for maternal and newborn care have proven successful as evident from a community-based trial in Uganda [3]. Further, Adam et al. found delivery of health messages by community health workers increased knowledge of maternal and newborn care among women in the local community [4]. A recent systematic review by Gilmore and colleagues suggest that FLWs are being widely utilized in middle and low income countries and there is evidence (albeit insufficient) to suggest that they could be an effective tool in reducing maternal and neonatal mortality [5]. Hence, in resource-constrained settings like ours, there is a huge potential for the role of community health workers in improving maternal and newborn care.

In India, FLWs (including Auxiliary Nurse Midwives (ANMs), Accredited Social Health Activists (ASHAs), and Anganwadi worker (AWWs)) form an integral part of the Indian healthcare system and are key elements of delivery of healthcare services in the community. They are the links between the community and the healthcare system and often first point of contact for people seeking care. The FLWs function as service extension workers and as activists for social change and play a pivotal role by supporting programs to improve access to healthcare and nutrition. They are female cadres of India's community health worker program selected from the community itself which helps in local and cultural acceptability of their roles by the community.

Presently, there is little data available in the Indian context that documents the frequency of contact with FLWs in promoting maternal and newborn related healthy behavior. Thus, the current analysis was undertaken to examine the effect of intensity of contact with FLWs on maternal and newborn health behaviors and to determine if the association varied by status of Self Help Group (SHG) membership. Uttar Pradesh (UP), the most populous state of India with high levels of poverty and low levels of social and economic development [6], has received unprecedented attention and strong political commitment from the state as well as national government in efforts aimed at improving maternal and child health and reducing related mortality. Yet, it still continues to perform poorly and contributes to 28 and $35 \%$ of neonatal and maternal deaths in the country [7]. As per the Sample Registration Survey 2013 (SRS, 2013), the estimates of MMR and IMR of UP are at 292 per 100,000 live births and 50 per 1000 live births respectively. Current analyses are performed using data from the baseline learning phase of the Uttar Pradesh Community Mobilization (UPCM) Project [8] (the details of which are described below) to better understand the experiences of integrating FLWs into health systems to improve maternal and newborn outcomes in a setting such as UP.

\section{Methods}

\section{Study design and settings}

The UPCM project utilized a pre-post interventioncontrol design. However, the current paper is an exploratory analysis that utilized data from the baseline survey of the UPCM project. The project, a 5-year initiative, started in 2011 with the aim to develop and scale up evidence-based interventions to achieve the goal of improving Reproductive, Maternal, Newborn and Child Health and Nutrition (RMNCHN) health behaviors among marginalized population in UP. The goal of this 1 project was to reduce neonatal mortality by improving maternal and child health behaviors through developing and scaling up a package of family health interventions and strengthening the management of Behavior Change Communication (BCC) using SHGs as a platform. In UP, the Rajiv Gandhi Mahila Vikas Pariyojana (RGMVP) working since 2002 developed a rapidly scalable SHG model organizing poor rural women into groups of 10-20 women and using them as platforms for building up family health interventions. All the SHGs mobilized at the village level are federated into village organizations (VOs) representing 150-250 women drawn from 10 to 20 SHGs. These VOs, in turn, are federated into Block Organizations (BOs) representing 5000-7000 women. The RGMVP 
program utilizes community health volunteers (called Swasthya Sakhi, SS) who are selected from among the members of SHG (1 SS per SHG). She is trained to counsel women and their families on key health behaviors. The SHG acts as a systemic interface between poor people and development initiatives. The RGMVP is an independent platform and is not directly linked to the existing healthcare delivery system.

The UPCM program under which the baseline survey was conducted, utilized the SSs and mobilized the community using the SHG platform. This social platform served as a vehicle for behavior change management $(\mathrm{BCM})$ as well as for improving health system access through collaboration with local level field workers. The UPCM project was not directly linked to the existing government health system; it was not involved in delivery of health services per se.

The baseline survey of the UPCM project was carried out in 5 districts (Sultanpur, Raebareli, Mirzapur, Maharajganj and Hardoi) in UP from June to August 2013. The districts were purposively selected based on geographical diversity and the presence of the SHGs. The current analyses utilized the overall data from baseline survey.

\section{Sampling and study population}

A two-staged sampling was used to first select districts and then required number of households (Please refer to Additional file 1: Box S1 for an overview of administrative division in India). In each block of the five selected districts, a house listing was done in all villages/purvas (group of SHGs) of the listed GPs to identify eligible women among SHG households. The house listing included the name of the household's head, the woman's name and the age of her last child during the survey. A complete enumeration of the listed eligible women was done to identify women from SHG households in intervention and control areas. Selection of respondents was done through availability of eligible woman at the time of sample collection. To identify eligible women from non-SHG households in the intervention area, a listing of non-SHG households was done in the neighborhood of SHG households in each selected village/purva to ensure similar socioeconomic characteristics of women in both the groups. The required number of non-SHG households (half of the sampled SHG households) was randomly selected from each village/purva. The eligibility criteria for inclusion into the sampling frame were (a) currently married women aged 15 to 49 years and (b) who had delivered a baby till 15 months prior to the survey. If there was more than one eligible woman per household, a random procedure was used to select the woman. The sampling strategy used was in line with the objectives of the baseline survey, that is, to establish equivalence of intervention and control areas with respect to background characteristics and to assess baseline level of maternal and child health practices between the two arms. However, for the purpose of this paper, the data from the overall sample was analyzed without differentiating it into intervention and control arms.

\section{Sample size}

Among the different indicators related to health behavior, change in percentage points of institutional delivery was used for calculating the sample size as it produced the largest sample size. A sample of 878 eligible women from SHG households was required in each arm (intervention and control) assuming a 20 percentage point increase in institutional delivery over 3 years with $80 \%$ power, (5\% confidence and $10 \%$ nonresponse rate. Additionally, to assess the diffusion effect in adoption of healthy behaviors, half the number (439) was required in the intervention area from households without SHG member. Thus, the total sample size required was 2195 eligible women $(878+878+439)$. However, a few additional women were interviewed and the final sample included 2208 women. This sample size calculation was meant to answer the main objective of UPCM project, that is, to measure the effect of $B C C$ intervention on healthy maternal and newborn behavior changes. The current analysis is only an exploratory study and used the overall data from the baseline learning survey.

\section{Study tool and measurements}

The baseline survey was conducted by the Population Council, one of the implementing partners and responsible for the Monitoring, Learning and Evaluation (MLE) activities of the project. Structured interviews (in Hindi) programmed on a computer-assisted personal interview (CAPI) package was orally administered to collect information using mini-laptops by specially trained field staff. Census and Survey Processing System (CSPro) software compatible with the mini-laptops was used. A series of internal consistency checks and logics were built into the CAPI package for data quality. The outcome of interest included variables related to knowledge and practice of healthy behavior in relation to maternal and newborn health. The knowledge indicators related to maternal health behavior considered for this analysis were binary responses to questions on availing at least 3 antenatal care (ANC) check-ups (those who reported this as "don't know" or "as many as required" were considered as "No"), taking at least two Tetanus Toxoid (TT) injections, consuming 100 or more Iron-Folic Acid (IFA) tablets, awareness of key danger signs during pregnancy, delivery and after delivery for which immediate attention was required; knowledge on key newborn 
health behavior included responses to questions on knowledge that nothing needs to be applied to cord stump, that breastfeeding needs to be initiated within $1 \mathrm{~h}$ following delivery and knowledge on how Kangaroo Mother care (KMC)/skin-to-skin is to be done. Practice of maternal health behavior was captured through key indicators like attended at least 3 ANCs, took at least two TT injections, consumed 100 or more IFA tablets, saved money for delivery, arranged transport for delivery, decided place of delivery, delivered at institution, sought treatment for complications during delivery and within 42 days after delivery and received any post-natal care (PNC) within 42 days of delivery. Key indicators on practice of newborn health behavior considered for this analysis were seeking treatment for danger signs experienced by newborn during first month of birth, applying nothing on cord stump, delaying bath till after $24 \mathrm{~h}$ of delivery, practicing $\mathrm{KMC} /$ skin-to-skin, breastfeeding within $1 \mathrm{~h}$ of delivery, and feeding mother's yellow thick milk to child.

FLW provides services in close proximity to the community [9]. These services include those that are delivered at home or family and through outreach sessions. These can be further categorized into services offered during pregnancy, delivery, and during neonatal period. In India, female health workers or ANMs take care of a population of 5000. ASHAs and AWWs are responsible for a population of 1000 each. SS. The SSs under the RGMVP program are mainly involved in facilitating awareness and ensuring women's access to healthcare services. Please refer to Additional file 1: Box S1 for further details on the different FLWs and their links with healthcare system.

For the purpose of this paper, the term "FLW" refers to community health workers under the Indian healthcare system including ANMs, ASHAs and AWWs and the SSs who are community volunteers under the RGMVP program. The exposure variable considered was intensity of contact with FLWs during pregnancy (measured as total number of contacts with either ANMs, ASHAs, AWWs or SSs). This was further arbitrarily categorized into three groups-no contact, 1-2 contacts, and $\geq 3$ contacts. In addition, information on other potential confounding variables like age, highest standard of education completed by women, if women presently working, religion of head of the family, caste of head of the family (a system of social stratification in India dividing Hindus into hierarchical groups; those belonging to scheduled caste, scheduled tribe and other backward classes are among the lower caste groups), wealth index, and history of previous stillbirth were collected.

\section{Statistical analysis}

All tests were performed using Stata 13 (StataCorp, College Station, TX, USA). Categorical variables as number of subjects and percentages while continuous variables were summarized as mean \pm standard deviation (SD). We used chi-square test to compare the differences in the distribution of categorical variables across groups that summarized frequency of visits to FLW. We examined the association of intensity of contact with FLW (independent variable of interest) with maternal and newborn health behavior practice indicators as the dependent variable, one at a time using regression models. Multilevel simple and multiple logistic regression with random intercept was used for analyses to account for the complex sampling design. We started by univariate analysis and subsequently fitted multivariable model adjusting for age, highest standard of education completed by women, if women presently working, religion of head of the family, caste of head of the family, wealth index, and history of previous stillbirth. To assess if the relation was modified by SHG membership, we included a multiplicative interaction parameter between SHG membership status and each of the practice indicators into the regression models. The significance level used for two-sided tests was $P<0.05$.

\section{Ethics}

The project proposal was reviewed and approved by Independent Ethics Committee of Population Council, New Delhi. Verbal consent for participation was obtained from the participants by the field interviewers before collecting the data.

\section{Results}

Analysis was done on a total of 2208 women, of whom $78 \%$ belonged to SHG household. Mean age of these women was $25.55 \pm 4.92$ years with only $52 \%$ having ever attended school and about $20 \%$ currently engaged in any form of work to earn either in cash/kind or both. The mean number of living children these women had was $2.60 \pm 1.56$ and about $6 \%$ of them reported pregnancies resulting in a stillbirth. Majority of them (93\%) were Hindus predominantly belonging to scheduled tribe (6\%), scheduled caste (47\%), or other backward class (35\%) (data not shown).

Table 1 describes women's contact with different frontline workers. The results show that during pregnancy, about $91 \%$ of women had some contact with at least one of the FLWs of whom $14 \%$ had 1-2 contacts and $77 \%$ had 3 or more contacts. Among those who had some contact, $81 \%$ reported contact with ANM; 78\% with ASHA; 35\% with AWW; and about 2\% with SS. The average number of contacts with ANM, ASHA, AWW and SS were 2.36, 3.02, 3.11, and 2.86, respectively.

Table 2 describes the distribution of key sociodemographic characteristics of the women across categories reflecting intensity of contact. All socio- 
Table 1 Contact with frontline worker (FLW) and intensity of contact

\begin{tabular}{lll}
\hline Contacts with FLW & $\mathrm{n}(\%)$ out of 2208 & $\begin{array}{l}\text { Average number } \\
\text { of contacts }\end{array}$ \\
\hline ANM & $1791(81.11)$ & 2.36 \\
ASHA & $1724(78.08)$ & 3.02 \\
AWW & $780(35.33)$ & 3.11 \\
SS & $42(1.90)$ & 2.86 \\
\hline
\end{tabular}

ANM auxiliary nurse midwives, $A S H A$ accredited social health activist, $A W W$ Anganwadi worker, SS Swasthya Sakhi

demographic characteristics considered in this analysis did not differ significantly with intensity of contact with FLWs except for presently working which showed a weak evidence of a difference. Distribution of knowledge and practice of key maternal healthy behaviors among women across categories summarizing intensity of contact is presented in Table 3. Over $50 \%$ women had knowledge that one must undergo at least 3 ANC check-ups, 57\% were aware of the need of two TT injections but less than one-third had knowledge about the need for consumption of 100 or more IFA tablets. For all these three maternal behaviors, knowledge showed a significant increasing trend with an increasing number of contacts $(P$ value $<0.001)$. Knowledge of danger signs/complications during pregnancy, delivery, and post-partum period requiring immediate attention was varied and ranged from $<1 \%$ for convulsions to about $20 \%$ for excessive vaginal bleeding during pregnancy and post-partum period (data not shown). With regard to practice of healthy maternal behaviors, 96\% of women reported having taken TT injections as a part of ANC check-ups during their last pregnancy. However, uptake of ANC check-ups and consumption of 100 or more IFA tablets were only 51 and $8 \%$ respectively even though awareness about them was slightly higher. Except for TT injections which showed an increasing trend with increasing number of contacts with FLW, there were no significant associations of ANC check-ups and IFA consumption with intensity of contact with FLW. Further, no associations were observed between delivery preparedness (comprising of saving money, arranging

Table 2 Distribution of key demographic characteristics according to intensity of contact with FLW

\begin{tabular}{|c|c|c|c|c|}
\hline & \multicolumn{4}{|c|}{ No. of contact with FLW } \\
\hline & $\begin{array}{l}0 \\
(N=202)\end{array}$ & $\begin{array}{l}1-2 \\
(N=316)\end{array}$ & $\begin{array}{l}\geq 3 \\
(N=1690)\end{array}$ & $P$ value \\
\hline Mean age of women in years (SD) & $25.15(5.50)$ & $24.99(4.48)$ & $25.70(4.92)$ & 0.100 \\
\hline \multicolumn{5}{|l|}{ Mean number of living children (SD) } \\
\hline Highest educational standard attained, $n(\%)$ & $95(47.03)$ & $172(54.43)$ & $888(52.54)$ & \multirow[t]{4}{*}{0.428} \\
\hline No education & $107(52.97)$ & $145(45.89)$ & $808(47.81)$ & \\
\hline Up to 10th standard & $71(35.15)$ & $137(43.35)$ & $703(41.60)$ & \\
\hline Above 10th standard ${ }^{a}$ & $24(11.88)$ & $34(10.76)$ & 179 (10.59) & \\
\hline Working for cash or kind, n (\%) & $35(17.33)$ & $54(17.09)$ & $368(21.78)$ & 0.078 \\
\hline \multicolumn{5}{|l|}{ Religion, $n(\%)$} \\
\hline Hindu & $186(92.08)$ & $285(90.19)$ & $1575(93.20)$ & \multirow[t]{2}{*}{0.161} \\
\hline Muslim & $16(7.92)$ & $31(9.81)$ & $115(6.80)$ & \\
\hline \multicolumn{5}{|l|}{ Caste, $n(\%)$} \\
\hline Scheduled caste/scheduled tribe & $113(55.94)$ & $162(51.27)$ & $897(53.08)$ & \multirow[t]{3}{*}{0.822} \\
\hline Other backward classes & $69(34.16)$ & $114(36.08)$ & $589(34.85)$ & \\
\hline Others & $20(9.90)$ & $40(12.66)$ & $204(12.07)$ & \\
\hline \multicolumn{5}{|l|}{ Wealth Index, $n(\%)$} \\
\hline Highest & $28(13.86)$ & $76(24.05)$ & $338(20.00)$ & \multirow[t]{4}{*}{0.208} \\
\hline Second & $42(20.79)$ & $62(19.62)$ & $338(20.00)$ & \\
\hline Third & $45(22.28)$ & $62(19.62)$ & $334(19.76)$ & \\
\hline Fourth and fifth quintile combined & $87(43.07)$ & $116(36.71)$ & $680(40.24)$ & \\
\hline \multicolumn{5}{|l|}{ Type of family, $n(\%)$} \\
\hline Nuclear & $85(42.08)$ & $123(38.92)$ & $784(46.39)$ & \multirow[t]{2}{*}{0.035} \\
\hline Non-nuclear & $117(57.92)$ & $193(61.08)$ & $906(53.61)$ & \\
\hline History of previous stillbirth & $17(8.42)$ & $18(5.70)$ & $103(6.09)$ & 0.396 \\
\hline
\end{tabular}

${ }^{\text {aTh }}$ category includes 11 th and12th standard, Bachelors, Post-graduates, Technical education after 10th standard and others combined 
Table 3 Distribution of key maternal knowledge and practice health indicators during pregnancy, delivery and after pregnancy according to intensity of contact with FLW

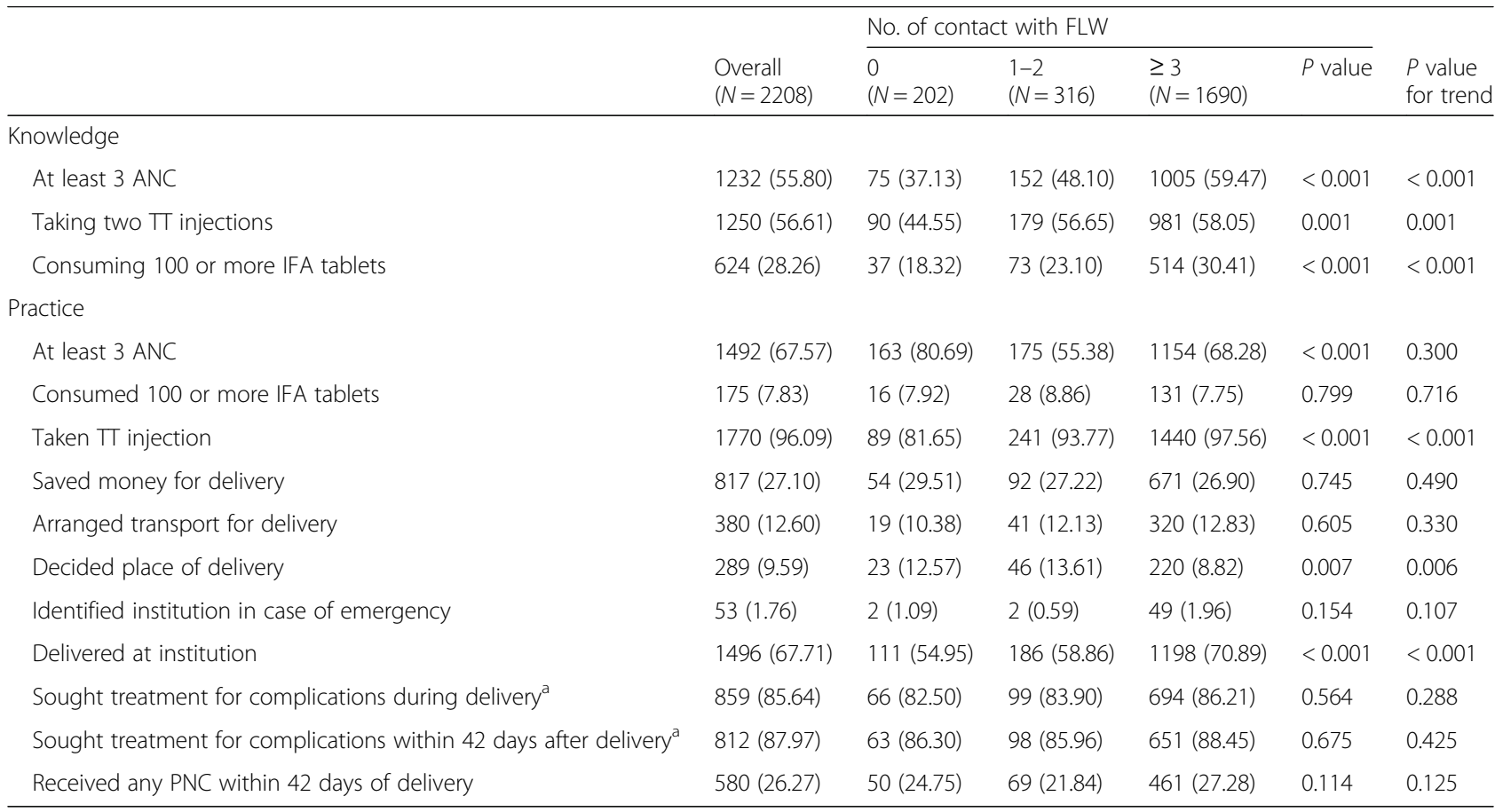

FLW frontline worker, ANC antenatal care, $T$ tetanus toxoid, IFA iron-folic acid, PNC postnatal care

a The denominator used were women reporting problems/complications and not the total sample $N$

transport, deciding place of delivery and identifying the institution in case of emergency), seeking treatment for complications during delivery and within 42 days after delivery with intensity of contact with FLWs. Only $68 \%$ of these women reported having delivered their last child at an institution and the proportion increased with increasing number of contact with FLWs $(P$ value $<0.001)$.
Knowledge of key newborn healthy behaviors was limited to the awareness that breastfeeding should be initiated within $1 \mathrm{~h}$ (Table 4) of delivery while awareness on thermal care (KMC/skin-to-skin) and knowledge that nothing is to be applied to the cord stump was very poor (about 3\%). Practice of breastfeeding within $1 \mathrm{~h}$ of delivery was observed in $50 \%$ of the women. Similarly, $56 \%$ of women reported delayed bath of newborn till

Table 4 Distribution of key newborn knowledge and practice health indicators according to intensity of contact with FLW

\begin{tabular}{|c|c|c|c|c|c|c|}
\hline & \multirow[b]{2}{*}{$\begin{array}{l}\text { Overall } \\
(N=2208)\end{array}$} & \multicolumn{4}{|c|}{ No. of contact with FLW } & \multirow[b]{2}{*}{$\begin{array}{l}P \text { value } \\
\text { for trend }\end{array}$} \\
\hline & & $\begin{array}{l}0 \\
(N=202)\end{array}$ & $\begin{array}{l}1-2 \\
(N=316)\end{array}$ & $\begin{array}{l}\geq 3 \\
(N=1690)\end{array}$ & $P$ value & \\
\hline \multicolumn{7}{|l|}{ Knowledge } \\
\hline Knowledge that nothing needs to be applied to cord stump & $93(3.40)$ & $5(2.02)$ & $12(3.13)$ & $76(3.61)$ & 0.407 & 0.190 \\
\hline Knowledge that breastfeeding should be initiated within $1 \mathrm{~h}$ & $1285(58.20)$ & $93(46.04)$ & $171(54.11)$ & $1021(60.41)$ & $<0.001$ & $<0.001$ \\
\hline Know how KMC/skin-to-skin care is done & $49(3.42)$ & $3(2.46)$ & $3(1.65)$ & $43(3.81)$ & 0.275 & 0.190 \\
\hline \multicolumn{7}{|l|}{ Practice } \\
\hline $\begin{array}{l}\text { Sought treatment for danger signs experienced by newborn } \\
\text { during first month of birth }\end{array}$ & $2041(84.48)$ & $145(82.39)$ & $285(84.82)$ & $1611(84.61)$ & 0.725 & 0.555 \\
\hline Applied nothing on cord stump & $601(23.85)$ & $52(22.71)$ & $89(24.86)$ & $460(23.80)$ & 0.832 & 0.905 \\
\hline Delayed bath (after 24 h) & $1255(56.84)$ & $96(47.52)$ & $167(52.85)$ & $992(58.70)$ & 0.003 & 0.001 \\
\hline Practice KMC/skin-to-skin & $59(3.31)$ & $2(1.39)$ & $5(2.30)$ & $52(3.66)$ & 0.237 & 0.091 \\
\hline Breastfeeding within $1 \mathrm{~h}$ & $1072(49.52)$ & $70(36.46)$ & $129(41.48)$ & $873(52.53)$ & $<0.001$ & $<0.001$ \\
\hline Fed mother's yellow thick milk to child & $1836(83.15)$ & $155(76.73)$ & $265(83.86)$ & $1416(83.79)$ & 0.038 & 0.034 \\
\hline
\end{tabular}

FLW frontline worker, KMC Kangaroo Mother Care

${ }^{a}$ The denominator used were new born children reporting danger signs 
after $24 \mathrm{~h}$ of delivery. Both practices showed increasing trends with increasing number of contacts with FLW.

Tables 5 and 6 describe the crude and adjusted associations of practice of maternal and newborn healthy behavior respectively with intensity of contact with FLW. The odds of taking TT injection was 5 and 6 times more in those who had 1-2 and $\geq 3$ contacts respectively as compared to those with no contacts $(P$ value $<0.001)$. However, no such association was observed with the uptake of at least 3 ANCs. A similar increase in odds of delivering in an institution was observed in those who had higher number of contacts as compared to those with no contacts $(P$ value $<0.001)$. With regard to newborn healthy behavior practice, breastfeeding within $1 \mathrm{~h}$ of delivery showed significant association and the odds of this practice improved in those who had $\geq 3$ contacts with FLW as compared to those had no contacts. Except for consumption of 100 or more IFA tablets, we did not find evidence of any interaction of these associations by SHG status, suggesting that associations between contact with FLW and healthy behavior did not significantly differ by SHG membership (that is, there was no additional benefit of being an SHG member).

\section{Discussion}

In this baseline survey of currently married women aged 15 to 49 years predominantly Hindus belonging to scheduled tribe/scheduled caste or other backward classes, we observed an overall low prevalence of both knowledge and practice of key maternal and newborn healthy behaviors. IFA consumption, one of the key maternity care component determining maternal health, was discouragingly low among this sample of women. It is difficult to decipher (in the absence of supporting data) if observed low prevalence is because of gaps in the supply chain or the fact that pregnant women are reluctant to take it. However, recent evidence from another part of rural India suggest that not only sociodemographic determinants but ANC factors like timing, frequency, and quality play a key role in facilitating consumption [10]. The same study observed more likelihood of women consuming IFA if it is available in stock on important village days like Village Health and Nutrition Day (VHND).

Very low knowledge on newborn healthy practices like care of cord stump and $\mathrm{KMC} /$ skin-to-skin care was reported. This could be a reflection of the fact that although these practices have traditionally been a part of intervention initiatives for child survival but guidelines and policies under the National program were not in place until the recent years [11] and may not have been widely implemented. Further, there was surprisingly high practice of cord care in spite of very low knowledge on the same. This is difficult to explain; but a probable

Table 5 Crude and adjusted associations of practice of maternal healthy behavior with intensity of contact with FLW

\begin{tabular}{|c|c|c|c|c|c|c|c|c|}
\hline \multirow[b]{3}{*}{ Practice indicators } & \multicolumn{7}{|c|}{ No. of contact with FLW } & \multirow{3}{*}{$\begin{array}{l}P \text { value for } \\
\text { interaction }\end{array}$} \\
\hline & \multirow{2}{*}{$\begin{array}{l}0 \\
(N=202) \\
\text { Ref }\end{array}$} & \multicolumn{2}{|l|}{$\begin{array}{l}1-2 \\
(N=316)\end{array}$} & \multicolumn{2}{|l|}{$\begin{array}{l}\geq 3 \\
(N=1690)\end{array}$} & \multicolumn{2}{|l|}{$P$ value } & \\
\hline & & $\begin{array}{l}\text { Crude OR } \\
(95 \% \mathrm{Cl})\end{array}$ & $\begin{array}{l}\text { Adjusted } \\
(95 \% \mathrm{Cl})\end{array}$ & $\begin{array}{l}\text { Crude } \\
(95 \% \mathrm{Cl})\end{array}$ & $\begin{array}{l}\text { Adjusted } \\
(95 \% \mathrm{Cl})\end{array}$ & Crude & Adjusted & \\
\hline At least 3 ANC check-ups & {$[1]$} & $\begin{array}{l}0.28 \\
(0.18-0.42)\end{array}$ & $\begin{array}{l}0.29 \\
(0.16-0.53)\end{array}$ & $\begin{array}{l}0.47 \\
(0.32-0.68)\end{array}$ & $\begin{array}{l}0.63 \\
(0.37-1.08)\end{array}$ & $<0.001$ & $<0.001$ & 0.751 \\
\hline $\begin{array}{l}\text { Consumed } 100 \text { or more IFA } \\
\text { tablets }\end{array}$ & {$[1]$} & $\begin{array}{l}1.06 \\
(0.55-2.01)\end{array}$ & $\begin{array}{l}0.88 \\
(0.40-1.95)\end{array}$ & $\begin{array}{l}0.84 \\
(0.48-1.46)\end{array}$ & $\begin{array}{l}0.72 \\
(0.37-1.41)\end{array}$ & 0.537 & 0.538 & 0.018 \\
\hline Taken $T$ injection & {$[1]$} & $\begin{array}{l}4.15 \\
(2.76-6.23)\end{array}$ & $\begin{array}{l}4.52 \\
(2.36-8.65)\end{array}$ & $\begin{array}{l}7.03 \\
(5.00-9.88)\end{array}$ & $\begin{array}{l}5.86 \\
(3.50-9.82)\end{array}$ & $<0.001$ & $<0.001$ & 0.739 \\
\hline Saved money for delivery & {$[1]$} & $\begin{array}{l}0.89 \\
(0.60-1.34)\end{array}$ & $\begin{array}{l}0.93 \\
(0.54-1.59)\end{array}$ & $\begin{array}{l}0.90 \\
(0.64-1.25)\end{array}$ & $\begin{array}{l}0.84 \\
(0.54-1.31)\end{array}$ & 0.816 & 0.674 & 0.348 \\
\hline Arranged transport for delivery & {$[1]$} & $\begin{array}{l}1.16 \\
(0.65-2.08)\end{array}$ & $\begin{array}{l}1.25 \\
(0.58-2.71)\end{array}$ & $\begin{array}{l}1.27 \\
(0.77-2.10)\end{array}$ & $\begin{array}{l}1.35 \\
(0.70-2.60)\end{array}$ & 0.580 & 0.662 & 0.963 \\
\hline Decided place of delivery & {$[1]$} & $\begin{array}{l}1.15 \\
(0.66-2.01)\end{array}$ & $\begin{array}{l}1.02 \\
(0.47-2.23)\end{array}$ & $\begin{array}{l}0.78 \\
(0.48-1.26)\end{array}$ & $\begin{array}{l}0.81 \\
(0.42-1.55)\end{array}$ & 0.078 & 0.566 & 0.462 \\
\hline Delivered at institution & {$[1]$} & $\begin{array}{l}1.04 \\
(0.70-1.55)\end{array}$ & $\begin{array}{l}0.67 \\
(0.35-1.29)\end{array}$ & $\begin{array}{l}1.61 \\
(1.15-2.25)\end{array}$ & $\begin{array}{l}1.10 \\
(0.62-1.94)\end{array}$ & 0.001 & 0.064 & 0.252 \\
\hline $\begin{array}{l}\text { Sought treatment for complications } \\
\text { during delivery }\end{array}$ & {$[1]$} & $\begin{array}{l}1.21 \\
(0.50-2.95)\end{array}$ & $\begin{array}{l}1.10 \\
(0.31-3.95)\end{array}$ & $\begin{array}{l}1.23 \\
(0.59-2.56)\end{array}$ & $\begin{array}{l}1.97 \\
(0.67-5.77)\end{array}$ & 0.857 & 0.236 & 0.500 \\
\hline $\begin{array}{l}\text { Sought treatment for complications } \\
\text { within } 42 \text { days after delivery }\end{array}$ & {$[1]$} & $\begin{array}{l}0.97 \\
(0.39-2.44)\end{array}$ & $\begin{array}{l}1.23 \\
(0.16-9.45)\end{array}$ & $\begin{array}{l}1.14 \\
(0.53-2.44)\end{array}$ & $\begin{array}{l}0.35 \\
(0.07-1.79)\end{array}$ & 0.863 & 0.102 & 0.113 \\
\hline $\begin{array}{l}\text { Received any PNC within } 42 \text { days of } \\
\text { delivery }\end{array}$ & [1] & $\begin{array}{l}0.80 \\
(0.51-1.25)\end{array}$ & $\begin{array}{l}0.76 \\
(0.42-1.38)\end{array}$ & $\begin{array}{l}0.93 \\
(0.64-1.35)\end{array}$ & $\begin{array}{l}0.87 \\
(0.53-1.44)\end{array}$ & 0.542 & 0.659 & 0.888 \\
\hline
\end{tabular}


Table 6 Crude and adjusted associations of practice of newborn health behavior with intensity of contact with FLW

\begin{tabular}{|c|c|c|c|c|c|c|c|c|}
\hline \multirow[b]{3}{*}{ Practice indicators } & \multicolumn{7}{|c|}{ No. of contact with FLW } & \multirow{3}{*}{$\begin{array}{l}P \text { value for } \\
\text { interaction }\end{array}$} \\
\hline & \multirow{2}{*}{$\begin{array}{l}0 \\
(N=202) \\
\text { Ref }\end{array}$} & \multicolumn{2}{|l|}{$\begin{array}{l}1-2 \\
(N=316)\end{array}$} & \multicolumn{2}{|l|}{$\begin{array}{l}\geq 3 \\
(N=1690)\end{array}$} & \multicolumn{2}{|l|}{$P$ value } & \\
\hline & & $\begin{array}{l}\text { Crude OR } \\
(95 \% \mathrm{Cl})\end{array}$ & $\begin{array}{l}\text { Adjusted } \\
(95 \% \mathrm{Cl})\end{array}$ & $\begin{array}{l}\text { Crude } \\
(95 \% \mathrm{Cl})\end{array}$ & $\begin{array}{l}\text { Adjusted } \\
(95 \% \mathrm{Cl})\end{array}$ & Crude & Adjusted & \\
\hline $\begin{array}{l}\text { Sought treatment for danger signs experienced by } \\
\text { newborn during first month of birth }\end{array}$ & [1] & $\begin{array}{l}1.26 \\
(0.75-2.11)\end{array}$ & $\begin{array}{l}1.00 \\
(0.46-2.17)\end{array}$ & $\begin{array}{l}1.21 \\
(0.78-1.87)\end{array}$ & $\begin{array}{l}1.09 \\
(0.56-2.12)\end{array}$ & 0.648 & 0.925 & 0.133 \\
\hline Applied nothing on cord stump & [1] & $\begin{array}{l}1.20 \\
(0.80-1.82)\end{array}$ & $\begin{array}{l}1.36 \\
(0.73-2.54)\end{array}$ & $\begin{array}{l}1.02 \\
(0.72-1.46)\end{array}$ & $\begin{array}{l}1.56 \\
(0.91-2.67)\end{array}$ & 0.508 & 0.242 & 0.659 \\
\hline Delayed bath (after 24 h) & [1] & $\begin{array}{l}1.19 \\
(0.82-1.72)\end{array}$ & $\begin{array}{l}0.99 \\
(0.56-1.73)\end{array}$ & $\begin{array}{l}1.32 \\
(0.97-1.81)\end{array}$ & $\begin{array}{l}1.13 \\
(0.70-1.83)\end{array}$ & 0.182 & 0.714 & 0.801 \\
\hline Practice KMC/skin-to-skin & [1] & $\begin{array}{l}1.69 \\
(0.32-9.03)\end{array}$ & $\begin{array}{l}1.17 \\
(0.20-6.87)\end{array}$ & $\begin{array}{l}2.55 \\
(0.60-10.82)\end{array}$ & $\begin{array}{l}1.25 \\
(0.27-5.77)\end{array}$ & 0.334 & 0.957 & \\
\hline Breastfeeding within $1 \mathrm{~h}$ & [1] & $\begin{array}{l}1.11 \\
(0.76-1.63)\end{array}$ & $\begin{array}{l}0.78 \\
(0.45-1.33)\end{array}$ & $\begin{array}{l}1.67 \\
(1.21-2.31)\end{array}$ & $\begin{array}{l}1.29 \\
(0.82-2.04)\end{array}$ & $<0.001$ & 0.013 & 0.784 \\
\hline Fed mother's yellow thick milk to child & [1] & $\begin{array}{l}1.49 \\
(0.94-2.35)\end{array}$ & $\begin{array}{l}0.58 \\
(0.25-1.33)\end{array}$ & $\begin{array}{l}1.38 \\
(0.95-1.99)\end{array}$ & $\begin{array}{l}0.74 \\
(0.35-1.56)\end{array}$ & 0.180 & 0.390 & 0.582 \\
\hline
\end{tabular}

FLW frontline worker, KMC Kangaroo Mother Care

explanation could be that because all information was collected based on recall it is likely that recall for practice of a healthy behavior was easier as compared to that for knowledge.

Practice of institutional delivery, TT injection, and breastfeeding within $1 \mathrm{~h}$ of delivery was significantly associated with contact with FLW and an increasing trend was observed with increasing intensity of contact with FLW. Except for relationship between IFA consumption and contact with FLW, there was no significant interaction by SHG membership status for any of the other associations.

Among the key maternal health behaviors studied, only knowledge on the need for $\geq 3$ ANCs and TT injection were significantly associated with contact with FLWs. In spite of the recommended 3 (and more recently 4) ANC check-ups, uptake of minimum required ANC visits remains low [12, 13]. Women perceive ANC care as unnecessary [14] and pregnancy as a natural phenomenon not requiring special care [15]. Uptake of ANCs check-ups in the current analysis was observed to have reduced with increasing number of contacts with FLWs. This can probably be attributed to the fact that any contact with FLW is being utilized by women for ANC counseling /check-ups and that the women did not feel the need to attend antenatal clinics in a health facility for the same if they already had some contact with a FLW. Although antenatal care is one of the strongest predictors of institutional delivery [16], we observed a high prevalence of the same in the study population in spite of low ANC coverage. The presence of an association between institutional delivery and TT injection with intensity of contact with FLW is not surprising given that maternal and child health related programs in India have been aggressively promoting institutionalization of deliveries and universal immunization of pregnant women against tetanus. Additionally, contact with FLWs probably helps to further reinforce the message and motivate the women.

The current study revealed that increasing the number of contacts with FLWs did not have any effect on knowledge of essential newborn care, in particular, cord care and thermal care but had a significant effect on initiation of breast feeding within an hour. Although the average number of contacts with different FLWs was close to 3 yet these interactions were not effectively advancing healthy behavior among the women and a commensurate improvement in awareness and behavior change towards maternal and newborn care. This could be a reflection of the fact that intensity of contact with FLWs alone does not necessarily determine healthy practices but may largely be driven by quality of services provided by FLWs. The success of delivery of maternal and newborn health care services depends largely on adequate training of FLWs; sound knowledge and good quality of services rendered by FLWs can materialize to better awareness and healthy practices in the community. Indeed, there are evidences to suggest that knowledge and practices of FLW on maternal health are far from adequate and there is a need for regular re-training and evaluation $[17,18]$.

With regard to the number of contacts with a FLW, it has been shown that contact within first $48 \mathrm{~h}$ of delivery has the greatest impact on Neonatal Mortality Rate (NMR). There is inconclusive evidence on the relationship between number of home visits and NMR. Moreover, how much would be the impact of community based interventions on NMR depends largely on the baseline NMR (more than 50 per 1000 live births) and coverage $(\geq 50 \%)$ in the population $[19,20]$. 
Globally, there is renewed interest in the engaging frontline workers in maternal and child health, particularly, in low and middle income countries where shortage of human resources necessitates their involvement to increase capacity of constrained health systems. The literature reveals evidence showing promising benefits of utilizing lay health workers in health programs, in particular, in promoting immunization and breastfeeding uptake and subsequently reducing child morbidity and mortality [21]. Other systematic reviews support these findings and have demonstrated the effectiveness of community health workers in low- and middle-income countries in delivering preventive interventions for maternal and child health [5] and preventing perinatal and maternal death by improving antenatal, perinatal and postpartum service delivery [22].

In the Indian healthcare system, FLWs play a critical role in the delivery of primary health care to promote community health and nutrition for rural communities. The FLW undergoes extensive training to dispense their roles which mainly cover preventative aspects of maternal, new-born and child care. They provide a basket of essential preventive primary care for Reproductive, Maternal, Newborn, Child, and Adolescent health $(\mathrm{RMNCH}+\mathrm{A})$ services and are linked to government health facilities where they refer pregnant woman, new-born and children for care. The ASHAs, in particular, are also incentivized under specific programs to promote maternal care i.e. promote institutional delivery and conduct postnatal care in the community. The RGMVP program in UP working for poverty reduction, women's empowerment, and rural development, used an innovative scalable demand-side SHG model as a social platform to promote not only social and empowerment agendas but also health behavior change in select districts. While government cadre of FLWs were well established and functional in the select districts at the time of baseline survey, the saturation of the villages with the SSs under the RGMVP was still under way. The current network of FLWs under the existing government health system and the volunteers (SSs) under the RGMVP program provided a good opportunity for the UPCM project to layer the proposed health intervention. However, any observed (positive or negative) association between ANC check-ups and intensity of contacts from the present analyses is independent of the UPCM project.

Moving beyond FLWs to mobilizing community volunteers is recognized as another instrumental way that can be combined for collective action to have a sustainable impact on maternal and health outcomes. Incorporating community-based interventions through different approaches have resulted in improvement of health outcomes of mother and newborn. A recent systematic review on effect of participatory learning and action involving women's group in low-resource setting showed how this approach can be used as a cost effective strategy to improve maternal and newborn survival [23]. Closer home, the Shivgarh trial in one district of Uttar Pradesh successfully demonstrated reduction in NMR through implementation of essential newborn care intervention package using a Behavior Change Management (BCM) approach by community mobilizers and volunteers [24]. Further, Ekjut trial in Jharkhand and Orissa in India [25] and other community mobilization efforts across neighboring countries like Bangladesh [26, 27] and Nepal [28] show evidence supporting the same. In fact, the Ekjut study demonstrated additional effects like continuation of practices post withdrawal of the trial [29]. An interesting finding in this trial was that the more marginalized benefitted most from the intervention than the less marginalized suggesting inequalities in neonatal mortality can be reduced through community-based participatory intervention [30].

Along the same lines, the potential role of social platforms like SHG in health care delivery in low- and middle-income countries has garnered attention and they have shown to complement existing health care services helping to achieve some degree of synergy between health care providers and users [31]. The current implementation project took advantage of the SHG platform initiated by RGMVP to implement their intervention involving $\mathrm{BCM}$ approach. At the time of the baseline survey, the RGMVP had institutionalized SHG platform in over 37 districts (including the selected districts for baseline survey) in UP with an aim to saturate villages with them. Except for IFA consumption, associations of contact with FLWs and other maternal and newborn healthy practice did not differ by SHG membership status of the women. Considering that these are findings from the baseline survey before the intervention was rolled out, it could be that although SHGs were well-established they were not adequately leveraged for promoting healthy behavior for maternal and newborn care; it is then not surprising to see no effect modification of these associations by SHG membership. Even if SHGs were existing and were functional, there is the possibility that SHG's monthly meetings, a forum for execution of their agenda, i.e., to spread awareness among its members on health services, were not effectively being utilized. This could explain the absence of any additional effect of SHG membership on the associations between health behavior and contact with FLW.

The strengths of this study are its population-based design and reasonably large sample size. The study is limited by several factors. Assessments of maternal and newborn health indicators relied on a long recall period of 15 months and this could have an influence on the findings. While knowledge reflected awareness at time of 
survey, indicators of healthy behavior was assessed for practices that were followed during pregnancy, delivery, and post-partum. Hence, gap in knowledge and practice to assess for quality of care for the population could not be determined. Another potential limitation is the crosssectional nature of the survey which does not allow us to infer causality. We did not have information on important potential confounders like distance and functionality of nearby health facility and could not adjust for them. Further, this survey covered section of the population predominantly belonging to SC/ST and other backward classes, hence generalizing the findings to a larger population would be debatable.

\section{Conclusion}

In conclusion, the baseline survey showed lack of knowledge of maternal and newborn care and poor practice of healthy behaviors among women and a few statistically significant associations with intensity of contact with FLW. The results brought to light the fact that contact with FLW does not necessarily bring about a behavioral change in people; probably quality of services provided by FLW and timings of contact may be crucial. Building a sustainable impact on maternal and newborn health might require moving beyond FLWs (as just the agents of change) to community mobilization through platforms like SHGs. Such participatory approach should be taken advantaged of to provide a way forward for more scalable strategies. However, these findings need to be interpreted in the context of the organizational and programmatic aspects and functionality of the health system keeping in mind that FLW and/or SHG alone cannot bring about the desired reduction in maternal and child mortality.

\section{Additional file}

Additional file 1: Box S1. Overview of administrative and healthcare system in India, frontline workers under government health system and Rajiv Gandhi Mahila Vikas Pariyojana (RGMVP) (DOCX 15 kb)

\section{Abbreviations}

ANC: Antenatal care; ANM: Auxiliary nurse midwives; ASHA: Accredited social health activist; AWW: Anganwadi worker; BCC: Behavior change communication; BCM: Behavior change management; CAPI: Computerassisted personal interview; CSPro: Census and survey processing system; FLW: Frontline worker; GP: Gram Panchayat; IFA: Iron-folic acid; IMR: Infant mortality rate; KMC: Kangaroo Mother Care; MDG: Millennium Development Goal; MLE: Monitoring learning and evaluation; MMR: Maternal mortality ratio; NMR: Neonatal mortality rate; PNC: Postnatal care; RGMVP: Rajiv Gandhi Mahila Vikas Pariyojana; RMNCHN: Reproductive, Maternal, Newborn and Child Health and Nutrition; SD: Standard deviation; SDG: Sustainable development goal; SHG: Self-help groups; SS: Swasthya Sakhi; TT: Tetanus toxoid; UP: Uttar Pradesh; UPCM: Uttar Pradesh Community Mobilization

\section{Acknowledgements}

This publication used secondary data collected by Population Council for the Bill and Melinda Gates Foundation (BMGF) funded "Uttar Pradesh Community Mobilization Behavior" consortium project. The consortium consisted of Public Health Foundation of India (PHFI), Rajiv Gandhi Mahila Vikas Pariyojana (RGMVP) Population Council (PC) and Boston University (BU).

\section{Funding}

This project is funded by Bill and Melinda Gates Foundation (Grant number: OPPI033910) awarded to Public Health Foundation of India. The funding agency had no role in design, conduct of the study, analysis, and interpretation of the results and writing of this manuscript.

\section{Availability of data and materials}

Please contact author for data requests.

\section{Authors' contributions}

TL, DM, DA, and SS conceived and designed the concept for this paper. TL analyzed the data and drafted the manuscript. SN, DM, DA, and SS contributed to redrafting and finalizing of the final manuscript. All authors read and approved the final manuscript.

\section{Ethics approval and consent to participate}

This project proposal was reviewed and approved by Independent Ethics committee of Population Council, New Delhi. Verbal consent for participation was obtained from the participants by the field interviewers before collecting the data.

\section{Consent for publication}

Not applicable.

\section{Competing interests}

The authors declare that they have no competing interests.

\section{Publisher's Note}

Springer Nature remains neutral with regard to jurisdictional claims in published maps and institutional affiliations.

\section{Author details}

${ }^{1}$ Indian Institute of Public Health Delhi, Public Health foundation of India, New Delhi, India. ${ }^{2}$ Public Health foundation of India, New Delhi, India. ${ }^{3}$ Indian Institute of Public Health Gandhinagar, Public Health Foundation of India, New Delhi, India. ${ }^{4}$ Indian Institute of Public Health Delhi, Public Health foundation of India, Plot No. 47, Sector-44, Institutional Area, Gurgaon 122002, India.

Received: 24 November 2016 Accepted: 28 November 2017

Published online: 08 January 2018

\section{References}

1. Strategic approach to Reproductive. Maternal, newborn and child + adolescent health. New Delhi: Ministry of Health and Family Welfare, Government of India; 2013. http://nhm.gov.in/images/pdf/programmes/rmncha-strategy.pdf

2. http://www.unic.org.in/items/India_and_the_MDGs_small_web.pdf.

3. Waiswa P, Pariyo G, Kallander K, Akuze J, Namazzi G, Ekirapa-Kiracho E. Effect of the Uganda newborn study on care-seeking and care practices: a clusterrandomised controlled trial. Glob Health Action. 2014;7:24584.

4. Adam MB, Dillmann M, Chen MK, Mbugua S, Ndung'u J, Mumbi P, et al. Improving maternal and newborn health: effectiveness of a community health worker program in rural Kenya. PLoS One. 2014:9(8):e104027.

5. Gilmore B, McAuliffe E. Effectiveness of community health workers delivering preventive interventions for maternal and child health in low- and middleincome countries: a systematic review. BMC Public Health. 2013;13:847.

6. Bajpai N, Sachs JD. India's decade of development: looking back at the last 10 years and looking forward to the next 20 CGC. Working paper no. 3. 2011.

7. Available from: https://rgmvp.org/program-impacts/. Accessed 15 Dec 2017.

8. Khan ME, Agrawal PK, Hazra A, Dixit A, Bhatnagar I, Ahmad J, et al. Maternal and newborn health behaviours in rural Uttar Pradesh: findings from learning phase baseline survey, 2013. New Delhi: Population Council; 2014.

9. Nair N, Tripathy P, Prost A, Costello A, Osrin D. Improving newborn survival in low-income countries: community-based approaches and lessons from South Asia. PLoS Med. 2010;7(4):e1000246.

10. Wendt A, Stephenson R, Young M, Webb-Girard A, Hogue C, Ramakrishnan $U$, et al. Individual and facility-level determinants of iron and folic acid receipt and adequate consumption among pregnant women in rural Bihar, India. PLoS One. 2015;10(3):e0120404. 
11. National Health Mission. Kangaroo mother care and optimal feeding of low birth weight infants - operational guidelines. New Delhi: National Health Mission, MoHFW; 2014.

12. Tiwari S, Nigam R, Waware RS, Chandorkar RK. Health care seeking behaviour and awareness of maternal and child health practices in a Rural Village of Madhya Pradesh. Natl J Community Med. 2014;5(1):105-8.

13. Gupta RK, Shora TN, Verma AK, Jan R. Knowledge regarding antenatal care services, its utilization, and delivery practices in mothers (aged 15-49 years) in a rural area of North India. Trop J Med Res. 2015;18:89-94.

14. Laishram J, Thounaojam UD, Panmei J, Mukhia S, Devi HS. Knowledge and practice of ante-natal care in an urban area. Indian Medical Gazette. 2013;2013:101-6.

15. Metgud C, Katti S, Mallapur M, Wantamutte A. Utilization patterns of antenatal services among pregnant women: a longitudinal study in rural area of north Karnataka. Al Ameen J Med Sci. 2009:2(1):58-62.

16. Kamal SM. Preference for institutional delivery and caesarean sections in Bangladesh. J Health Popul Nutr. 2013;31(1):96-109.

17. Kohli C, Kishore J, Sharma S, Nayak H. Knowledge and practice of accredited social health activists for maternal healthcare delivery in Delhi. Journal of family medicine and primary care. 2015;4(3):359-63.

18. Kharat SM, Sagare SM, Gothankar JS, Jadhav KP. Knowledge and practices of maternal health care amongst auxiliary nurse midwives in Pune District International J of Healthcare and Biomedical Research. 2015;3(2):149-55.

19. Gogia S, Ramji S, Gupta P, Gera T, Shah D, Mathew JL, et al. Community based newborn care: a systematic review and metaanalysis of evidence: UNICEF-PHFI series on newborn and child health. India Indian pediatrics. 2011:48(7):537-46

20. Gogia S, Sachdev HS. Home visits by community health workers to prevent neonatal deaths in developing countries: a systematic review. Bull World Health Organ. 2010;88(9):658-6B.

21. Lewin S, Munabi-Babigumira S, Glenton C, Daniels K, Bosch-Capblanch X, van Wyk BE, et al. Lay health workers in primary and community health care for maternal and child health and the management of infectious diseases. The Cochrane database of systematic reviews. 2010;3:CD004015.

22. Bhutta ZA, Lassi ZS, Pariyo G, Huicho L. Global experience of community health workers for delivery of health related millennium development goals: a systematic review, country case studies, and recommendations for integration into National Health Systems. Global Health Workforce Alliance. 2010;2010:249-61.

23. Prost A, Colbourn T, Seward N, Azad K, Coomarasamy A, Copas A, et al. Women's groups practising participatory learning and action to improve maternal and newborn health in low-resource settings: a systematic review and meta-analysis. Lancet. 2013;381(9879):1736-46.

24. Kumar V, Mohanty S, Kumar A, Misra RP, Santosham M, Awasthi S, et al. Effect of community-based behaviour change management on neonatal mortality in Shivgarh, Uttar Pradesh, India: a cluster-randomised controlled trial. Lancet. 2008;372(9644):1151-62.

25. Tripathy P, Nair N, Barnett S, Mahapatra R, Borghi J, Rath S, et al. Effect of a participatory intervention with women's groups on birth outcomes and maternal depression in Jharkhand and Orissa, India: a cluster-randomised controlled trial. Lancet. 2010;375(9721):1182-92.

26. Azad K, Barnett S, Banerjee B, Shaha S, Khan K, Rego AR, et al. Effect of scaling up women's groups on birth outcomes in three rural districts in Bangladesh: a cluster-randomised controlled trial. Lancet. 2010;375(9721):1193-202.

27. Fottrell E, Azad K, Kuddus A, Younes L, Shaha S, Nahar T, et al. The effect of increased coverage of participatory women's groups on neonatal mortality in Bangladesh: a cluster randomized trial. JAMA Pediatr. 2013;167(9):816-25.

28. Manandhar DS, Osrin D, Shrestha BP, Mesko N, Morrison J, Tumbahangphe $\mathrm{KM}$, et al. Effect of a participatory intervention with women's groups on birth outcomes in Nepal: cluster-randomised controlled trial. Lancet. 2004; 364(9438):970-9.

29. Roy SS, Mahapatra R, Rath S, Bajpai A, Singh V, Rath S, et al. Improved neonatal survival after participatory learning and action with women's groups: a prospective study in rural eastern India. Bull World Health Organ. 2013;91(6):426-33B.

30. Houweling TA, Tripathy P, Nair N, Rath S, Rath S, Gope R, et al. The equity impact of participatory women's groups to reduce neonatal mortality in India: secondary analysis of a cluster-randomised trial. Int J Epidemiol. 2013; 42(2):520-32.

31. Nayar K, Kyobutungi C, Razum O. Self-help: what future role in health care for low and middle-income countries? Int J Equity Health. 2004;3(1):1.

\section{Submit your next manuscript to BioMed Central and we will help you at every step:}

- We accept pre-submission inquiries

- Our selector tool helps you to find the most relevant journal

- We provide round the clock customer support

- Convenient online submission

- Thorough peer review

- Inclusion in PubMed and all major indexing services

- Maximum visibility for your research

Submit your manuscript at www.biomedcentral.com/submit 